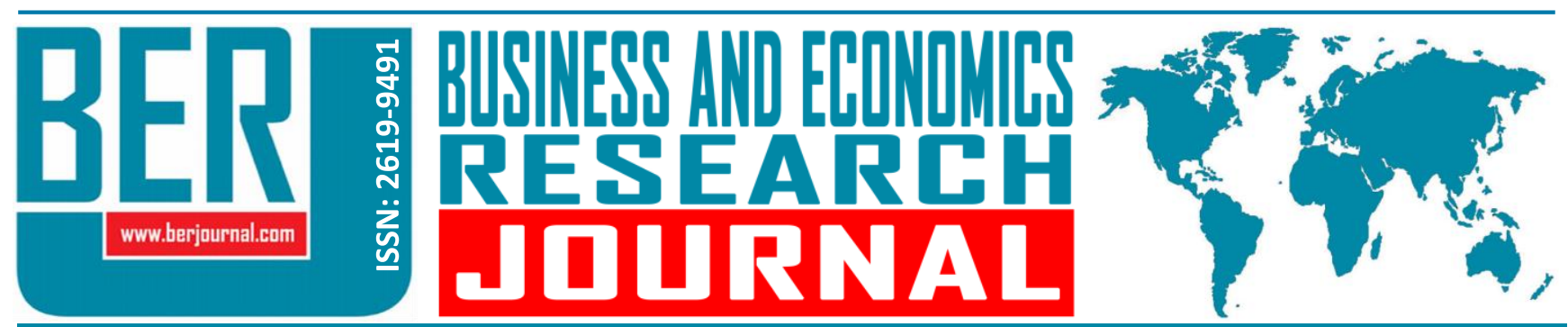

Business and Economics Research Journal Vol. 10, No. 4, 2019, pp. 833-844 doi: 10.20409/berj.2019.204

\section{Geleceğe Yönelik Değerlendirmelere İlişkin Özel Durum Açıklamalarının Pay Senedi Fiyatları Üzerindeki Etkisi: Borsa İstanbul Örneği}

\begin{abstract}
Saim Kilic ${ }^{\mathrm{a}}$
Öz: Çalışmada, Ocak 2014 - Ocak 2019 döneminde payları Borsa Istanbul'da işlem gören şirketler tarafından geleceğe yönelik değerlendirmeler kapsamında yapılan özel durum açıklamalarının (bildirimlerin) pay senetleri fiyatları üzerindeki etkisi incelenmiştir. $\mathrm{Bu}$ amaçla, söz konusu dönemde 23'ü olumlu nitelikte ve 20'si olumsuz nitelikte olmak üzere toplam 43 adet bildirim inceleme kapsamına alınmış ve Olay Çalışması yöntemi ile analiz edilmiştir. Araştırma sonuçlarına göre, ilk olarak, geleceğe yönelik değerlendirmelere ilişkin bildirimlerin genel olarak pay senetlerinin getirisi ve yatırımcıların kararları üzerinde etkili olduğuna dair istatistiksel olarak anlamlı bulgular elde edilmiştir. Ikinci olarak, olumlu nitelikteki bildirimlerin etkisi ile olumsuz nitelikteki bildirimlerin etkisi karşılaştırılmış olup; olumsuz bildirimlerin ilk etkisinin olumlu bildirimlerin ilk etkisinden daha güçlü olduğu, buna karşılık olumsuz bildirimlerin etkisinin olumlu bildirimlerin etkisinden daha kısa sürdüğü görülmüştür. Özellikle, olumlu bildirimlerin büyük çoğunluğunun açıklamadan itibaren beş işlem gününe kadar, olumsuz bildirimlerin büyük çoğunluğunun ise üç işlem gününe kadar fiyatlar üzerinde etkili olduğu gözlenmiştir.
\end{abstract}

\section{Impact of Forward Looking Disclosures on Stock Prices: Evidence from Borsa İstanbul}

Abstract: The study examines the impact of disclosures of forward looking statements by companies listed on Borsa istanbul on stock prices during the period of January 2014 - January 2019. For this purpose, a total of 43 disclosures, 23 of which were positive and 20 of which were negative, were included in the study and analyzed by the Event Study method. According to the results of the study, firstly, it has been found that forward looking disclosures have statistically significant impact on stock returns and investor's investment decisions. Secondly, when the impact of the positive disclosures and the impact of the negative disclosures were compared; it has been seen that the first impact of the negative disclosures is stronger than the first impact of the positive disclosures, whereas the effect of the negative disclosures lasts shorter than the effect of the positive disclosures. Especially it has been observed that a great majority of the positive disclosures have been effective on the stock prices up to next five transaction days and a great majority of the negative disclosures on the next three transaction days.
Anahtar Sözcükler: Geleceğe Yönelik Değerlendirmeler Geleceğe Dönük Beklentiler, Özel Durum Açıklamaları, Anormal Getiri, Olay Çalışması

JEL: G14, G19

$\begin{array}{ll}\text { Geliş } & : \text { 13 Mart } 2019 \\ \text { Düzeltme } & : 15 \text { Nisan } 2019 \\ \text { Kabul } & : 24 \text { Nisan } 2019 \\ & \\ \text { Tür } & \text { : Araştırma }\end{array}$

Keywords: Forward Looking Statements, Forward Looking Information, Disclosure, Abnormal Return, Event Study

JEL: G14, G19

$\begin{array}{ll}\text { Received } & : 13 \text { March } 2019 \\ \text { Revised } & : 15 \text { April } 2019 \\ \text { Accepted } & : 24 \text { April } 2019 \\ & \\ \text { Type } & \text { : Research }\end{array}$

Type : Research 


\section{Giriş}

Sermaye piyasalarında yatırımcılar esas olarak beklentiler ve kamuya açıklanan bilgiler çerçevesinde yatırım kararı alırlar. Yatırımcıların bu kararları da, sermaye piyasası araçlarının arz ve talebini ve dolayısıyla da fiyatını etkiler. Bu nedenle, sermaye piyasasının güvenilir, şeffaf, etkin, istikrarlı, adil ve rekabetçi bir ortamda işleyişini sağlamanın temeli yatırımcıların zamanında, tam ve doğru bir şekilde bilgilendirilmesinden geçmektedir. Bu olgu, Etkin Piyasalar Hipotezinin temelini oluşturmaktadır.

Yatırımcıların kararlarına ve beklentilerine esas teşkil eden bilgilerin başında, finansal tablo ve raporlar gelmektedir. Ancak, yalnızca geçmiş döneme ilişkin sonuçları gösteren finansal tablo ve raporlar, yatırımcıya sınırlı bilgi sunmaktadır. Zira yatırımcının doğru karar alabilmesi için şirketin pay senedinin fiyatını tahmin etmesi gerekir. Bu tahmin de sadece geçmiş bilgilerle yapılamaz. Herb Brody'in dediği gibi “Geçmişe bakarak geleceği tahmin etmek, her şeyin aynı kalacağı varsayımına dayanır. Bu durum, bir arabayı dikiz aynasından bakarak kullanmaya benzer." (Peters ve Kurt, 2014: 4). Dolayısıyla, pay senedinin fiyatı veya yatırımcıların kararları üzerinde şirketin geleceğe dönük beklentileri de önemli rol oynar. Şirketin satışlar, faaliyet dışı gelirler, yatırımlar, işletme sermayesi ihtiyacı, nakit akımları, hisse başına kar, sermaye yapısı, kâr payı gibi finansal kalemlere ilişkin projeksiyonları, gelecekteki faaliyetlerine ilişkin yönetimin plan ve hedefleri ile bunlara esas teşkil eden varsayımlar hakkında bilgi sahibi olan yatırımcının daha doğru karar alacağı şüphesizdir. Ayrıca, geleceğe yönelik bilgilerin paylaşılmasının, vekalet teorisi bağlamında, yatııımcıların karar alma süreçlerini geliştirmek yanında piyasadaki bilgi asimetrisini azaltma ve şirketlerin finansman maliyetlerini düşürme etkisi de bulunmaktadır (Aljifri ve Hussainey, 2007). Bu nedenlerle, şirketin geleceğe yönelik değerlendirmelerinin bir şekilde kamuya açıklanmasının sağlanması önem kazanmış olup; çoğu ülkede ihtiyari olmak üzere, şirketlerin bu değerlendirmelere yıllık faaliyet raporlarında yer vermeleri ve/veya yıllık faaliyet raporları dışında özel durum bildirimi, basın duyurusu, yatırımcı sunumu gibi yollarla kamuya açıklamaları esası benimsenmiştir.

Türkiye'de "geleceğe yönelik değerlendirmeler" kavramı ilk kez 23.01.2014 tarihinde Resmî Gazetede yayımlanan Sermaye Piyasası Kurulu’nun II.15.1 sayılı Özel Durumlar Tebliği ile özel olarak düzenlenmiştir. Söz konusu Tebliğ'de, geleceğe yönelik değerlendirmeler, "geleceğe ilişkin içsel bilgi niteliğindeki plan ve tahminleri içeren veya yatırımcılara ihraçının gelecekteki faaliyetleri ile finansal durumu ve performansı hakkında fikir veren değerlendirmeler" şeklinde tanımlanmıştır. Uygulamada, geleceğe yönelik değerlendirmeler yerine "geleceğe dönük beklentiler" kavramı da kullanılmaktadır.

Anılan Tebliğ uyarınca, Türkiye'de geleceğe yönelik değerlendirmelerin kamuya açıklanması zorunlu değildir. Geleceğe yönelik değerlendirmelerin gönüllü olarak kamuya açıklanmak istenmesi halinde ise, bazı kurallara uyulması şart tutulmuştur. Öncelikle, bu açıklamanın ya özel durum açıklaması şeklinde ya da kamuya açıklanan faaliyet raporları veya yatırımcı sunumları aracılığıyla yapılması gerekmektedir. Şirketler bu konuda yılda en fazla dört defa kamuya açıklama yapabilirler. Geleceğe yönelik olarak kamuya açıklanmış değerlendirmelerde önemli bir değişiklik ortaya çıktığında, yeni bir açıklama yapılması zorunludur. Geleceğe yönelik değerlendirmelere ilişkin olarak yapılacak açıklamalarda, daha önce kamuya açıklanan hususlar ile gerçekleşmeler arasında önemli ölçüde bir farklııı bulunması halinde, bu farklılıkların nedenlerine yer verilmelidir.

Bu noktada, "şirketlerin gönüllü olarak kamuya açıkladıkları geleceğe yönelik değerlendirmelere karşı yatırımcılar gerçekten beklendiği gibi karşılık vermekte midir? Başka bir deyişle, geleceğe yönelik değerlendirmelerin pay senetlerinin fiyatları üzerinde anlamlı bir etkisi bulunmakta mıdır?" soruları akla gelmektedir. Mevcut literatüre bakıldığında, bu alandaki çalışmaların birkaç istisna (Örneğin Çin'deki geleceğe yönelik zorunlu kamuyu açıklamaları inceleyen Qu, Ee, Liu, Wise ve Carey (2005) çalışması) hariç genelde gönüllü kamuya açıklamalar üzerine yoğunlaştığı ve bu çalışmalara esas teşkil eden verinin de şirketlerin faaliyet raporlarından elde edildiği görülmektedir.

Frankel, Mcnichols ve Wilson vd (1995), Core (2001), Healy ve Palepu (2001), Lundholm ve Van Wikle (2006) çalışmalarında vekalet teorisi kapsamında gönüllü kamuya açıklamaların bilgi asimetrisini ve dolayısıyla da sermaye maliyetini azaltıp azaltmadığını incelemişlerdir. Botosan (1997), Botosan ve Plumee (2002), Bozzolan, Favotto ve Ricceri (2003), Kent ve Ung (2003), Beattie, McInnes ve Fearnley (2004), Baginski, 
Hassell ve Kimbrough (2004), Bretta ve Bozzolan (2008), Menicucci (2013), Tutino, Regoliosi ve D'Eri (2013) geleceğe yönelik gönüllü kamuya açıklamaların içeriğinin kalitesi ile nicel ve nitel özelliklerini analiz etmişlerdir. Frost (1996), Lam ve Du (2004), Leuz ve Verecchia (2000) geleceğe yönelik değerlendirmelerin açıklanmasının ülkeler arasında farklılık gösterip göstermediğini araştırmışlardır. Vanstraelen vd. (2003), Kent ve Ung (2003), Aljifri ve Hussainey (2007), Çelik, Ecer ve Karabacak (2006), Uyar ve Kılıç (2012), Alkhatib (2014) geleceğe yönelik değerlendirmelerin gönüllü olarak yapılması için şirketleri motive eden faktörleri detaylı olarak incelemişlerdir. Sengupta (1998, Dontoh (1989), Francis vd (2004), Skinner (1994), Drake ve Peavy (1995), Botosan (1997), Lang ve Lundholm (1996), Krishnan, Sankaraguruswamy ve Shin (1996), Baginski vd. (2004) geleceğe yönelik değerlendirmeleri açıklanmasında fayda-maliyet analizine odaklanmışlardır.

Literatürdeki bazı çalışmalar da özel olarak kamuya açıklanan bilgilerin şirketlerin gelecek performansı hakkında bilgi sunup sunmadığını ve yatırımcıların karar almalarına yardımcı olup olmadığını araştırmışlardır. Clarkson, Kao ve Richardson $(1994,1999)$, faaliyet raporlarında yer alan geleceğe ilişkin açıklamaların şirketlerin gelecek performansı hakkında bir fikir verdiğini; Bryan (1997), faaliyet raporlarındaki geleceğe ilişkin faaliyet ve sermaye harcaması bilgileri ile şirketin kısa vadeli performansı arasında ilişki olduğunu; Barron, Kile ve O’Keefe (1999), geleceğe yönelik değerlendirmeler ile analistlerce yapılan tahminler arasında pozitif ilişki bulunduğunu; Bozzolon, Trombetta ve Beretta (2009) geleceğe yönelik değerlendirmelerin tahminlerin doğruluğunu etkilediği ve analist tahminlerindeki dağılmayı azalttığını; Amir ve Lev (1996), faaliyet raporlarda yer alan geleceğe dönük bilgilerin getiri - gelir ilişkisini geliştirdiğini; Miller ve Piotroski (2000), geleceğe yönelik beklentilere ilişkin açıklamaların pay senedinin getirisi ile şirketin bir sonraki dönem gelirleri arasındaki korelasyonu artırdığını; Dutta ve Trueman (2002), Wagenhofer (1990), Ackert, Church ve Sankar (1998), geleceğe yönelik bilgilerin yatırımcıların kararlarında etkili olduğunu; Skogsvik (1998), geleceğe dönük beklentilerin pay senedinin değerleme sürecinde dikkate alındığını; Eaton ve Stanga (2000), geleceğe yönelik bilgilerin bilgiyi kullananların karar verme etkinliğini artırdığını; Bravo (2016), geleceğe yönelik açıklamaların pay senedinin getirisindeki oynaklığı azalttığını ortaya koymuştur.

Öte yandan, literatüre bakıldığında, Borsa İstanbul'a ilişkin olarak bu konuda sınırlı sayıda çalışma yapıldığı görülmektedir. Örneğin Eyüboğlu ve Bulut (2016), özel durum açıklamalarını değişik gruplara ayırarak pay senedi fiyatlarına etkisini incelemiştir. Çalışmada Ocak 2003-Aralık 2012 döneminde BiST-30' da işlem gören şirketler tarafından duyurulan 2143 haberin incelenmesi sonucunda, yatırımcıların sırasıyla operasyonel haberlere $(\% 5)$, yeniden yapılanmaya ilişkin haberlere $(\% 1,8)$ ve finansal haberlere $(\% 1,5)$ tepki verdiğini tespit etmiştir. Çalışmada ele alınan finansal haberlerin kapsamı oldukça geniş olup, geleceğe dönük değerlendirmeler tek başına değil diğer haberlerle birlikte değerlendirilmiştir. Çelik vd. (2006) tarafından yapılan çalışmada, payları Borsa İstanbul'da işlem gören şirketlerin faaliyet raporlarında yer alan geleceğe dönük açıklamaların yapılmasında hangi faktörlerin etkili olduğu araştırılmıştır. Araştırma sonuçlarına göre, söz konusu açıklamaların şirketin büyüklüğü ve yabancı tekliflerle olan ilişkisinin pozitif; şirketin ortaklık yapısı, karlıı̆̆ı, yabancı yatırımları ve kurumsal yatırımcı oranı ile negatif yönde ilişkisi olduğu, ayrıca faaliyet ve finans şirketlerinin imalat şirketlerinden daha fazla bilgi açıkladıkları tespit edilmiştir. Uyar ve Kılıç (2012) tarafından yapılan çalışmada ise Borsa İstanbul'da işlem gören imalat şirketlerinin faaliyet raporlarında yer verilen geleceğe yönelik beklentilere ilişkin açıklamalar incelenmiştir. Çalışma sonunda, geleceğe yönelik açıklamaların çok yaygın olmadığı, yapılan açıklamaların büyük bölümünün nitel bilgilerden oluştuğu, olumlu nitelikteki beklentilerin daha fazla açıklandığı, şirket büyüklüğü ile bağımsız denetçinin tanınırlığının geleceğe yönelik açıklamaların yapılmasında etkili olduğu saptanmıştır.

Yukarıda kısaca özetlenen mevcut literatürden anlaşıldığı üzere, yıllık faaliyet raporları dışında özel durum açıklaması yoluyla kamuya duyurulan geleceğe yönelik değerlendirmelerin yatırımcıların kararlarına ve pay senedinin fiyatına etkisini henüz inceleme konusu yapılmamıştır. Esasen yıllık faaliyet raporları içinde yer alan geleceğe yönelik bilgilerin etkisini, söz konusu faaliyet raporlarında yer alan çok sayıdaki diğer bilgilerin etkisinden ayrıştırarak ölçmek oldukça zordur. Nitekim Türkiye için yapılan çalışmalarda da yalnızca faaliyet raporlarında yer alan açıklamaların içeriği ve nedenleri analiz edilmiş ancak açıklamaların getiri performansına etkisi incelenememiştir. Buna karşılık, geleceğe dönük beklentiler kapsamında spesifik olarak yapılmış özel durum açıklamalarından hareketle getiri performansını ölçmek daha uygun ve anlamlı bir yöntem olarak karşımıza çıkmaktadır. Sermaye Piyasası Kurulu'nun 2014 yılı başındaki düzenlemesi 
sayesinde, Borsa İstanbul'da bu kapsamda yapılmış özel durum açıklamaları verisi de oluşmuş bulunmaktadır. Dolayısıyla, bu çalışma ile şirketlerin geleceğe dönük değerlendirmelerinin pay senetlerinin getirisi üzerindeki etkisinin daha saf bir şekilde ölçülerek, literatüre katkı sağlanması amaçlanmıştır.

Çalışma önceki benzer çalışmalardan üç yönden farklılaşmaktadır. Birinci farklılık, geleceğe dönük beklentilerin açıklanmasının pay getirisine etkisinin Borsa İstanbul açısından ilk kez incelenmesidir. íkinci farklılık, faaliyet raporlarında yer alan geleceğe ilişkin açıklamaların değil, spesifik olarak bu amaçla yapılmış ve beş işlem günü öncesinde ve beş işlem günü sonrasında açıklanmış başka bilgi, olay veya gelişmenin bulunmadığı özel durum bildirimlerinin dikkate alınmasıdır. Böylece, geleceğe yönelik beklentilerin etkisinin net bir şekilde ölçülmesi hedeflenmiştir. Üçüncü olarak, her olay bazında, fiyat serisine uygun hem parametrik hem de parametrik olmayan testler birlikte uygulanmıştır.

Bu kapsamda, çalışma beş bölümden oluşmaktadır. Bundan sonraki ikinci bölümde, araştırmanın amacı ve kapsamı belirlenmiştir. Üçüncü bölümde, araştırmada kullanılan veri seti ve araştırmanın metodolojisi açıklanmıştır. Dördüncü bölümde, araştırma sonucunda elde edilen bulgulara yer verilmiştir. Son bölümde ise çalışmanın sonuçları kısaca özetlenmiştir.

\section{Araştırmanın Amacı ve Kapsamı}

Araştırmanın amacı, geleceğe yönelik değerlendirmelerin Sermaye Piyasası Kurulu'nca düzenlendiği 23.01.2014 tarihinden 23.01.2019 tarihine kadar geçen 5 yıllık süre içerisinde, payları Borsa İstanbul'da işlem gören şirketler tarafından geleceğe yönelik değerlendirmeler kapsamında yapılan özel durum açıklamalarının anılan şirketlerin pay senetleri fiyatları üzerindeki etkisini ampirik olarak test etmektir.

Kamuyu Aydınlatma Platformu resmi internet sitesinden (www.kap.org.tr) yapılan sorgulamada, söz konusu dönemde geleceğe yönelik değerlendirmeler kapsamında 273 adet özel durum açıklaması (bildirim) tespit edilmiştir. Anılan bildirimler incelendiğinde, geleceğe yönelik değerlendirmelerin bazılarında finansal tablo ve raporların açıklandığı, bazılarında ise pay senedinin fiyatını etkileyebilecek başka olay ve gelişmelere ilişkin açıklamaların yapıldığı tarih civarında olduğu görülmüştür. Araştırma ile amaçladığımız etkinin saf olarak ölçülebilmesi için, bu tür açıklamaların etkisinin elimine edilmesi gereği doğmuştur. Bu çerçevede, geleceğe dönük değerlendirmelere ilişkin bildirimin yapıldığı tarihten önceki beş ve sonraki beş işlem gününde finansal tablo ve raporlar ile başka önemli nitelikte olay ve gelişmeler açıklanmış ise, söz konusu bildirim kapsam dışında bırakılmıştır. Bu şekilde yapılan eliminasyon sonucunda analize elverişli 43 adet bildirim tespit edilmiş olup, bunların detayları Tablo 1'de yer almaktadır.

Söz konusu 43 adet bildirim belirlendikten sonra, bu bildirimler için iki husus daha açığa kavuşturulmuştur. Illk husus, analiz bakımından bildirimin yapıldığı günün (olay günü) ne olduğunun doğru tespit edilmesidir. Amaç yapılan özel durum açıklamasının etkisini ölçmek olduğuna göre; yapılan açıklamaların Borsa İstanbul'da seans devam ederken mi, yoksa seans sonrasında mı açıklandığı önem taşımaktadır. Bu nedenle, doğru analiz için, açıklamanın yapıldığı saat bilgisine bakılarak olay gününün (t0) yeniden belirlenmesi gereği doğmuştur. Eğer bildirim seans saatleri içerisinde yapılmışsa, olay günü (t0) olarak, bildirimin yapıldığı tarih dikkate alınmıştır. Eğer bildirim seans bittikten sonra yapılmışsa, olay günü (t0), bildirimin yapıldığı tarihten sonraki ilk işlem tarihi olarak belirlenmiştir.

Açıklığa kavuşturulan ikinci husus ise, söz konusu bildirimlerin piyasada olumlu mu yoksa olumsuz mu algılandığının saptanmasıdır. Zira analizin olumlu bildirimler ve olumsuz bildirimler şeklinde ayrım yapılarak gerçekleştirilmesi gerekmektedir. Bu amaçla, bir sonraki bölümde açıklanan model sonucunda elde edilen olay öncesine ilişkin anormal getiriler ve kümülatif anormal getiriler ile olay sonrasına ilişkin anormal getiriler ve kümülatif anormal getiriler hem gün ve hem de pencere bazında karşılaştırılarak etkinin negatif mi pozitif mi olduğu belirlenmiştir. Bu değerlendirme sonucunda, 43 adet bildirimin 23 adedinin olumlu ve 20 adedinin olumsuz bildirim niteliğinde olduğu anlaşılmıştır. Tablo 1 'de olumlu bildirimler ( $\uparrow)$, olumsuz bildirimler $(\downarrow)$ işaretiyle gösterilmiştir.

Nihai olarak araştırmamızda, 23.01.2014-23.01.2019 döneminde gerçekleşen 23 adedi olumlu ve 20 adedi olumsuz bildirim niteliğinde olan toplam 43 olay ele alınmıştır. 
Tablo 1. Geleceğe Yönelik Değerlendirmelere İlişkin Bildirimler

\begin{tabular}{|c|c|c|c|c|c|c|c|c|c|c|c|}
\hline Sayı & $\begin{array}{l}\text { Şirket } \\
\text { Kodu }\end{array}$ & $\begin{array}{c}\text { Bildirim } \\
\text { Tarihi }\end{array}$ & $\begin{array}{c}\text { Bildirim } \\
\text { Saati }\end{array}$ & $\begin{array}{c}\text { Olay } \\
\text { Günü (t0) }\end{array}$ & Etki & Sayı & $\begin{array}{l}\text { Şirket } \\
\text { Kodu }\end{array}$ & $\begin{array}{c}\text { Bildirim } \\
\text { Tarihi }\end{array}$ & $\begin{array}{c}\text { Bildirim } \\
\text { Saati }\end{array}$ & $\begin{array}{c}\text { Olay } \\
\text { Günü (t0) }\end{array}$ & Etki \\
\hline 1 & EKGYO & 15.12 .2014 & $13: 51$ & 15.12 .2014 & $\uparrow$ & 23 & GUBRF & 30.11 .2016 & $18: 36$ & 01.12 .2016 & $\downarrow$ \\
\hline 2 & THYAO & 31.12 .2014 & $17: 39$ & 02.01 .2105 & $\uparrow$ & 24 & DGKLB & 02.12 .2106 & 09:41 & 02.12 & $\downarrow$ \\
\hline 3 & ISCTR & 15.01 .2015 & $13: 27$ & 15.01 .2015 & $\uparrow$ & 25 & LOGO & 21.12 .2106 & $20: 16$ & 22.12 .2016 & $\downarrow$ \\
\hline 4 & GARAN & 16.01 .2015 & 09:29 & 16.01 .2015 & $\downarrow$ & 26 & EKGYO & 02.01 .2017 & $12: 24$ & 02.01 .2017 & $\uparrow$ \\
\hline 5 & TSKB & 16.01 .2015 & $17: 55$ & 19.01 .2015 & $\uparrow$ & 27 & GARAN & 11.01 .2 & $13: 02$ & 11.01 .2017 & $\downarrow$ \\
\hline 6 & BRISA & 15.04 .2015 & 18:19 & 16.04 .2015 & $\uparrow$ & 28 & HALKB & 12.0 & $18: 45$ & 13.0 & $\downarrow$ \\
\hline 7 & BRISA & 08.05 .2015 & 18:05 & 11.05 .2015 & $\downarrow$ & 29 & TSKB & 13.01 .2017 & $18: 14$ & 16.01 & $\uparrow$ \\
\hline 8 & ZOREN & 04.09 .2015 & $15: 23$ & 04.09 .2015 & $\uparrow$ & 30 & EKGYO & 24.03 .2017 & $19: 24$ & 27.03 & $\downarrow$ \\
\hline 9 & GOZDE & 10.11 .2015 & $16: 26$ & 10.11 .2015 & $\downarrow$ & 31 & GUBRF & 13.06.2017 & $12: 31$ & 13.06 .2017 & $\uparrow$ \\
\hline 10 & SAYAS & 24.12 .2015 & $12: 45$ & 24.12 .2015 & $\uparrow$ & 32 & EKGYO & 22.06 .2017 & $17: 40$ & 22.06 .2017 & $\uparrow$ \\
\hline 11 & AKBNK & 07.01 .2016 & 19:50 & 08.01 .2016 & $\uparrow$ & 33 & KORDS & 29.12 .2017 & $08: 36$ & 29.12 .2017 & $\uparrow$ \\
\hline 12 & GARAN & 08.01 .2016 & $9: 30 / 09: 5$ & 508.01 .2016 & $\uparrow$ & 34 & EKGYO & 09.0 & $10: 19$ & 09.01 .2018 & $\downarrow$ \\
\hline 13 & HALKB & 08.01 .2016 & $14: 21$ & 08.01 .2016 & $\uparrow$ & 35 & GARAN & 09.01 .2018 & 13:01 & 09.01 .2018 & $\downarrow$ \\
\hline 14 & TSKB & 08.01 .2016 & $18: 14$ & 11.01 .2016 & $\downarrow$ & 36 & ISCTR & 09.01 .2018 & $16: 47$ & 09.01.2018 & $\downarrow$ \\
\hline 15 & ISCTR & 11.01 .2016 & $15: 32$ & 11.01 .2016 & $\downarrow$ & 37 & TSKB & 18.01.2018 & $17: 36$ & 18.01 .2018 & $\downarrow$ \\
\hline 16 & GUBRF & 29.01 .2016 & $15: 50$ & 29.01 .2016 & $\downarrow$ & 38 & AKSA & 23.03 .2018 & $18: 25$ & 26.03 .2018 & $\uparrow$ \\
\hline 17 & LKMNH & 21.03 .2106 & $9: 28 / 10: 0$ & 21.03 .2016 & $\uparrow$ & 39 & CCOLA & 22.05 .2018 & $11: 35$ & 22.05 .2018 & $\downarrow$ \\
\hline 18 & GUBRF & 06.04 .2016 & $17: 55$ & 07.04 .2016 & $\uparrow$ & 40 & GARAN & 09.01 .2019 & 13:01 & 09.01.2019 & $\downarrow$ \\
\hline 19 & SAYAS & 16.06 .2016 & 08:50 & 16.06 .2016 & $\downarrow$ & 41 & ISCTR & 09.01.2019 & $16: 56$ & 09.01.2019 & $\uparrow$ \\
\hline 20 & LOGO & 06.09 .2016 & 13:54 & 06.09 .2016 & $\uparrow$ & 42 & PGSUS & 15.01 .2019 & $18: 18$ & 16.01 .2019 & $\downarrow$ \\
\hline 21 & ZOREN & 19.10 .2016 & $11: 45$ & 19.10 .2016 & $\uparrow$ & 43 & TSKB & 16.01 .2019 & $18: 10$ & 17.01 .2019 & $\uparrow$ \\
\hline 22 & EKGYO & 19.10 .2016 & $13: 26$ & 19.10 .2016 & $\uparrow$ & & & & & & \\
\hline
\end{tabular}

Kaynak: http://www.kap.org.tr

\section{Metodoloji ve Veri Seti}

Çalışmanın konusu olan geleceğe yönelik değerlendirmelere ilişkin bildirimlerin pay senedi üzerindeki etkisi, Olay Çalışması (Event Study) yönetimi ile analiz edilmiştir.

Olay Çalışması için anormal getirilerin hesaplanması gerekmektedir (Kılıç, 2011). Anormal getiri, gerçekleşen getiri ile beklenen teorik getiri arasındaki farktır. Anormal getirinin tahmin edilmesinde, bir regresyon modeli olan Piyasa Modeli kullanılacaktır. Bunun için de öncelikle modeldeki değişkenlerin belirlenmesi gerekir.

Modeldeki bağımlı değişken, her olay için, geleceğe yönelik değerlendirmelere ilişkin özel durum açıklaması yapan şirketin pay senetlerinin günlük getirisidir. Etkinin gücünü tam olarak görmek ve olası manipülasyon etkisini ortadan kaldırmak amacıyla, getiri hesaplamasına esas teşkil eden fiyatlar olarak, pay senedinin kapanış fiyatları değil gün içinde oluşan ağırlıklı ortalama fiyatları alınmıştır. Modelimizdeki bağımsız değişken ise söz konusu pay senedinin fiyatını açıklama gücüne sahip olan bir Borsa İstanbul endeksinin getirisi olmalıdır. Tablo 1'den de görüleceği üzere, kapsama dahil olan pay senetlerinin tamamına yakını BIST 100 kapsamında yer almaktadır. Bu sebeple, bağımsız değişken olarak BIST 100 Endeksi seçilmiştir.

Bu durumda, modelimiz aşağıdaki şekilde olacaktır (Kılıç, 2011):

$E(R j)=\alpha(j)+B(j) R m+\epsilon$

Modelde;

$E(R j)$, pay senedinin beklenen getirisini,

$\alpha(j)$, regresyon denklemindeki sabit değeri,

B(j), pay senedi fiyatının getirisi ile BIST 100 Endeksinin getirisi arasındaki ilişkiyi,

Rm ise BIST 100 Endeksinde gerçekleşen getiriyi,

$€$, hata terimini

ifade etmektedir. 
Bu çerçevede, pay senedinin olay günündeki (t0), olaydan sonraki 5 günlük zaman penceresindeki $(t+1, t+5)$ ve olaydan önceki 5 günlük zaman penceresindeki $(t-1, t-5)$ beklenen getirilerini tahmin etmek amacıyla, (t-5)'dan önceki 250 işlem günlerine (t-6, t-255) ait pay senedinin günlük düzeltilmiş ağırlıkı ortalama fiyatları ile BIST 100 Endeksinin günlük değerleri kullanılmıştır. Söz konusu veri, FINNET internet sitesinden (www.finnet.com.tr) temin edilmiştir. Önce, pay senetlerinin günlük getirileri hesaplanmıştır. Daha sonra, her olay için, 250 işlem gününe (t-6, t-255) ilişkin geçmiş veri kullanılarak, bu iki endeksin getirileri arasında bir regresyon analiziyle alfa ve beta katsayıları tahmin edilmiştir. Ardından da regresyon analizi sonucunda tahmin edilen alfa ve beta katsayıları modelde yerine konularak pay senedinin $(t-5, t+5)$ dönemi için gün bazında beklenen teorik getirileri bulunmuştur.

Beklenen getirilerin hesaplanmasını müteakip, aşağıdaki formül yardımıyla, $(t-5, t+5)$ penceresinde ilgili pay senedinin fiilen gerçekleşen getirisi ile beklenen getirisi arasındaki fark alınarak günlük Anormal Getirilere (AR) ulaşılmıştır.

$$
\begin{aligned}
& A R(j)=R j-E(R j) \\
& A R(j)=R j-[\alpha(j)+b(j) R m]
\end{aligned}
$$

Günlük anormal getirilerin hesaplanmasından sonra, açıklama öncesi döneme ilişkin 5 günlük (t-1, t5), 4 günlük ( $t-1, t-4), 3$ günlük (t-1, t-3) ve 2 günlük ( $t-1, t-2)$ pencereleri için; açıklama sonrası döneme ilişkin olarak da 5 günlük (to, $t+4), 4$ günlük (to, $t+3), 3$ günlük $(t 0, t+2)$ ve 2 günlük $(t 0, t+1)$ zaman pencereleri için Kümülatif Anormal Getiriler (CAR) elde edilmiştir.

Ayrıca çalışmada, çeşitli istatistiki testler yapılmıştır. Öncelikle, regresyon modelinin katsayılarının anlamlılığı test edilmiştir. İkinci olarak, Piyasa Modeli sonucunda elde edilen CAR değerlerinin değişik olay pencereleri için anlamlı olup olmadığı $t$ testi ile test edilmiştir. Üçüncü olarak, olay öncesi dönem için hesaplanan ortalama CAR değerleri ile olay sonrası dönem için hesaplanan ortalama CAR değerleri arasında pencereler bazında anlamlı bir fark olup olmadığı t testine tabi tutulmuştur. Son olarak, hem olay öncesi CAR ve olay sonrası CAR ortalamalarının farklılığının anlamlılı̆ını, hem de bu farklılığın ne kadar sürdüğünü (hangi pencerede etkili olduğunu) her bir olay bazında ölçmek amacıyla; biri parametrik, diğeri non-parametrik iki test uygulanmıştır. Parametrik test olarak, rastlantısal yürüyüş kuramı (random walk theory) uyarınca pay piyasasındaki fiyat değişikliklerinin bağımsız olduğu (Cootner, 1964) gözetilerek, bağımsız örneklem t testi kullanılmıştır. Bu testin varsayımının geçerliliğini (gruplara ilişkin verilerin normal dağılımlı olup olmadığını) belirlemek amacıyla Shapiro-Wilk testi gerçekleştirilmiştir (Akbulut, 2011; Büyüköztürk, 2012). Parametrik olmayan test olarak ise, Bağımsız Örneklem t-testinin muadili olan Mann-Whitney testi uygulanmıştır.

\section{Bulgular}

Payları Borsa İstanbul'da işlem gören şirketlerden 23.01.2014 - 23.01.2019 döneminde kamuya açıkladıkları 43 adet geleceğe yönelik değerlendirmeye ilişkin olarak çalışmamızda kullanılan ve anormal getirilerin hesaplanmasına esas teşkil regresyon modelinin genel olarak uygun olduğu ve tüm olaylar için hesaplanan açıklayıcı değişkenin (beta) \%95 güven aralığında istatistiksel olarak anlamlı olduğu (P değeri<0,05 veya t-Stat $>1,96)$ anlaşılmıştır. Söz konusu modelden elde edilen veriler çerçevesinde hem olumlu hem de olumsuz bildirimlere ilişkin olarak olay günü, olaydan önceki 5 gün ve olaydan sonraki 5 gün için günlük bazda hesaplanan anormal getirilerin (AR) ortalamaları Tablo 2'de; çeşitli zaman pencereleri için hesaplanan kümülatif anormal getirilerin (CAR) ortalaması ise Tablo 3 'te verilmektedir. 
Tablo 2. Açıklama Öncesi ve Sonrası Ortalama Anormal Getiriler (AR)

\begin{tabular}{c|ccc|ccc}
\hline \multirow{2}{*}{ Gün } & \multicolumn{3}{|c|}{ Olumlu Beklentiler } & \multicolumn{3}{c}{ Olumsuz Beklentiler } \\
\cline { 2 - 6 } & Olay Sayısı & Ortalama AR & Standart Sapma & Olay Sayısı & Ortalama AR & Standart Sapma \\
\hline$(\mathrm{t}-5)$ & & $-0,05 \%$ & 0,0107 & & $-0,20 \%$ & 0,0156 \\
$(\mathrm{t}-4)$ & $-0,39 \%$ & 0,0110 & & $0,20 \%$ & 0,0130 \\
$(\mathrm{t}-3)$ & & $-0,53 \%$ & 0,0094 & & $-0,04 \%$ & 0,0092 \\
$(\mathrm{t}-2)$ & $0,24 \%$ & 0,0128 & & $0,15 \%$ & 0,0152 \\
$(\mathrm{t}-1)$ & & $-0,47 \%$ & 0,0147 & & $1,39 \%$ & 0,0245 \\
$(\mathrm{t} 0)$ & 23 & $1,23 \%$ & 0,0151 & 20 & $-0,99 \%$ & 0,0166 \\
$(\mathrm{t}+1)$ & & $0,14 \%$ & 0,0128 & & $-0,48 \%$ & 0,0111 \\
$(\mathrm{t}+2)$ & $0,05 \%$ & 0,0113 & & $0,27 \%$ & 0,0103 \\
$(\mathrm{t}+3)$ & $0,20 \%$ & 0,0088 & & $0,29 \%$ & 0,0167 \\
$(\mathrm{t}+4)$ & & $0,28 \%$ & 0,0111 & & $0,51 \%$ & 0,0151 \\
$(\mathrm{t}+5)$ & $0,70 \%$ & 0,0200 & & $0,27 \%$ & 0,0224 \\
\hline
\end{tabular}

Tablo 3. Açıklama Öncesi ve Sonrası Pencere Bazında Kümülatif Anormal Getiriler (CAR)

\begin{tabular}{c|ccc|ccc}
\hline \multirow{2}{*}{ Pencere } & \multicolumn{3}{|c|}{ Olumlu Beklentiler } & \multicolumn{3}{c}{ Olumsuz Beklentiler } \\
\cline { 2 - 7 } & Ortalama CAR & Standart Sapma & T istatistiği & Ortalama CAR & Standart Sapma & T istatistiği \\
\hline$(\mathrm{t}-1, \mathrm{t}-5)$ & $-1,20 \%$ & 0,0301 & $-1,907^{*}$ & $1,49 \%$ & 0,0373 & $1,787^{*}$ \\
$(\mathrm{t}-1, \mathrm{t}-4)$ & $-1,15 \%$ & 0,0246 & $-2,239^{*}$ & $1,70 \%$ & 0,0314 & $2,415^{*}$ \\
$(\mathrm{t}-1, \mathrm{t}-3)$ & $-0,76 \%$ & 0,0195 & $-1,881^{*}$ & $1,49 \%$ & 0,0293 & $2,280^{*}$ \\
$(\mathrm{t}-1, \mathrm{t}-2)$ & $-0,23 \%$ & 0,0156 & $-0,720$ & $1,54 \%$ & 0,0254 & $2,703^{*}$ \\
$(\mathrm{t}-1)$ & $-0,47 \%$ & 0,0147 & $-1,543$ & $1,39 \%$ & 0,0245 & $2,536^{*}$ \\
$(\mathrm{t} 0)$ & $1,23 \%$ & 0,0151 & $3,894^{*}$ & $-0,99 \%$ & 0,0166 & $-2,656^{*}$ \\
$(\mathrm{t} 0, \mathrm{t}+1)$ & $1,36 \%$ & 0,0149 & $4,389^{*}$ & $-1,47 \%$ & 0,0219 & $-3,005^{*}$ \\
$(\mathrm{t} 0, \mathrm{t}+2)$ & $1,42 \%$ & 0,0202 & $3,368^{*}$ & $-1,20 \%$ & 0,0236 & $-2,281^{*}$ \\
$(\mathrm{t} 0, \mathrm{t}+3)$ & $1,61 \%$ & 0,0234 & $3,312^{*}$ & $-0,92 \%$ & 0,0329 & $-1,245$ \\
$(\mathrm{t} 0, \mathrm{t}+4)$ & $1,89 \%$ & 0,0252 & $3,608^{*}$ & $-0,41 \%$ & 0,0325 & $-0,558$ \\
\hline
\end{tabular}

Açıklama öncesi dönemler ile açıklama sonrası dönemler karşılaştıııldığında, gerek gün bazında ortalama anormal getirilerin (AR) ve gerekse çeşitli zaman pencereleri bazında ortalama kümülatif anormal getirilerin (CAR) farklılaştığı açıkça görülmektedir. Olay gününden önce negatif (pozitif) olan ortalama AR ve CAR değerleri, olay günü ve sonrasında pozitif (negatif) olmaktadır. Her iki bildirim tipinde de en yüksek getiri farklılığının olaydan bir gün önce ile olay günü arasında çıktığı anlaşılmaktadır. Olumlu bildirimlerin bir günde yarattığı anormal getiri farklılı̆ı \%1,70 iken, olumsuz bildirimlerinki -\%2,38' dir. Olumlu bildirimlerin etkisi beş gün devam ederken, olumsuz bildirimlerin etkisi daha kısa sürmektedir. Olay günü ve sonrası ortalama CAR değerlerinin olumlu bildirimler için bir günden beş güne kadar tüm zaman pencerelerinde, olumsuz bildirimler için ise bir günden üç güne kadar olan zaman pencerelerinde \%95 güven aralığında istatistiksel olarak anlamlı olduğu görülmektedir.

Tablo 4. Olay Öncesi ve Sonrası CAR Değerleri Ortalamaları Arasında t Testi

\begin{tabular}{|c|c|c|c|c|c|c|c|c|}
\hline \multirow[b]{2}{*}{$\begin{array}{c}\text { Karşılaştırılan } \\
\text { Pencereler }\end{array}$} & \multicolumn{4}{|c|}{ Olumlu Beklentiler } & \multicolumn{4}{|c|}{ Olumsuz Beklentiler } \\
\hline & \begin{tabular}{|c} 
Olay Öncesi \\
Penceresi CAR \\
Ortalaması
\end{tabular} & $\begin{array}{c}\text { Olay Sonrası } \\
\text { Penceresi CAR } \\
\text { Ortalaması }\end{array}$ & Fark & $\begin{array}{c}\text { P } \\
\text { Değeri }\end{array}$ & $\begin{array}{c}\text { Olay Öncesi } \\
\text { Penceresi CAR } \\
\text { Ortalaması }\end{array}$ & $\begin{array}{c}\text { Olay Sonrası } \\
\text { Penceresi CAR } \\
\text { Ortalaması }\end{array}$ & Fark & $\begin{array}{c}\mathbf{P} \\
\text { Değeri }\end{array}$ \\
\hline$(\mathrm{t}-1)$ ile $(\mathrm{t} 0)$ & $-0,47 \%$ & $1,23 \%$ & $1,70 \%$ & $0,0004^{*}$ & $1,39 \%$ & $-0,99 \%$ & $-2,38 \%$ & $0,0011^{*}$ \\
\hline$(\mathrm{t}-1, \mathrm{t}-2)$ ile $(\mathrm{t} 0, \mathrm{t}+1)$ & $-0,23 \%$ & $1,36 \%$ & $1,60 \%$ & $0,0009^{*}$ & $1,54 \%$ & $-1,47 \%$ & $-3,01 \%$ & $0,0003 *$ \\
\hline$(\mathrm{t}-1, \mathrm{t}-3)$ ile $(\mathrm{t} 0, \mathrm{t}+2)$ & $-0,76 \%$ & $1,42 \%$ & $2,18 \%$ & $0,0005^{*}$ & $1,49 \%$ & $-1,20 \%$ & $-2,70 \%$ & $0,0028^{*}$ \\
\hline$(\mathrm{t}-1, \mathrm{t}-4)$ ile $(\mathrm{t} 0, \mathrm{t}+3)$ & $-1,15 \%$ & $1,61 \%$ & $2,76 \%$ & $0,0003^{*}$ & $1,70 \%$ & $-0,92 \%$ & $-2,61 \%$ & $0,0143^{* *}$ \\
\hline$(\mathrm{t}-1, \mathrm{t}-5)$ ile $(\mathrm{t} 0, \mathrm{t}+4)$ & $-1,20 \%$ & $1,89 \%$ & $3,09 \%$ & $0,0005^{*}$ & $1,49 \%$ & $-0,41 \%$ & $-1,90 \%$ & $0,0948 * * *$ \\
\hline *\%1 seviyesinde anla & mli olduğunu gös & termektedir (P De & $\begin{array}{l}\text { eri }<0,01 \\
\text { ğeri }<0,0 \\
\text { Değeri }<0\end{array}$ & & & & & \\
\hline
\end{tabular}


Olay öncesi ve sonrası için belirlenen beş zaman penceresi için hesaplanan ortalama CAR değerleri arasında yapılan iki uçlu t testi sonuçları ise Tablo 4'de yer almaktadır. Olumlu bildirimler için iki dönem arasında hesaplanan anormal getiri farkları, ikinci pencerede hafif düşüş gösterse de genel olarak \%1,70'den başlayıp \%3,09'a kadar artarak devam etmektedir. Olay öncesi ve sonrası arasında hesaplanan bu farkların 5 zaman penceresinin tamamında \%99 güven aralığında istatistiksel olarak anlamlı olduğu anlaşılmaktadır. Olumsuz bildirimler için hesaplanan farklar ise \%2,38'dan başlayıp ikinci pencerede $\% 3,01^{\prime}$ e yükseldikten sonra üçüncü pencerede $\% 2,70$ 'e, dördüncü pencerede $\% 2,61^{\prime}$ e ve son pencerede $\% 1,90$ 'a düşmektedir. Bu eğilimi teyit eder bir şekilde, olumsuz bildirimlere ilişkin iki dönem arasındaki farklılığın ilk 3 zaman penceresinde \%99 güven aralığında, dördüncü zaman penceresinde \%95 güven aralığında ve beşinci zaman penceresinde \%90 güven aralığında istatistiksel olarak anlamlı olduğu görülmektedir.

Bu noktada analizimiz biraz daha ileriye götürülerek, bu kez her bir olay bazında, dönemler arası farklılığın anlamlılığı test edilmiştir. Bu kapsamda, her olay için, bir parametrik (Bağımsız Örneklem $t$ testi ve bu testin varsayımı olan normal dağııımı ölçmek için Shapiro-Wilk testi) ve bir de söz konusu testin muadili olan parametrik olmayan test (Mann-Whitney testi) gerçekleştirilmiştir. Bu testler yapılırken, gerek bildirim etkisinin esas olarak 5 gün sürdüğü ve gerekse de yapılacak testlerin 5 günden kısa dönem karşılaştırmasına imkân vermemesi nedeniyle, olay öncesi ve olay sonrası dönem uzunluğu 5 gün olarak belirlenmiştir.

Olumlu bildirimler için, her olay (bildirim) bazında, olay öncesi dönem CAR değerleri ile olay sonrası CAR değerleri arasındaki farklılı̆ın anlamlılığını ölçen parametrik ve parametrik olmayan test sonuçlarının özetine Tablo 5'te yer verilmiştir. Biri hariç 22 olayda, Shapiro-Wilk p-değerleri 0,05 'ten büyük elde edildiğinden hem olay öncesi döneme hem de olay sonrası döneme ilişkin grupların normal dağılım gösterdiği anlaşılmaktadır. Dolayısıyla, bu 22 olay için Bağımsız Örneklem t testi yorumlanabilir niteliktedir. Bağımsız Örneklem t testi sonuçlarına göre, 22 olayın 16'sında \%95 güven aralığında, 1'inde \%90 güven aralığında anlamlı farklılık tespit edilmiştir. Parametrik olmayan Mann-Whitney testi de benzer sonuçlar vermiş olup, 23 adet olayın 17'sinde \%95 güven aralığında anlamlı farklılık gözlemlenmiştir. Özetle, her 4 olumlu bildirimin yaklaşık 3'ünde, yapılan bildirimin pay senedinin fiyatını 5 işlem günü boyunca etkilediği ortaya çıkmakta olup, yukarıdaki tespitlerimizi teyit etmektedir.

Tablo 5. Olumlu Bildirimler İçin Olay Öncesi ve Sonrası Kümülatif Anormal Getirilerine ilişkin Shapiro-Wilk Testi, Bağımsız Örneklem t Testi ve Mann-Whitney Test Sonuçları

\begin{tabular}{|c|c|c|c|c|}
\hline \multirow{2}{*}{$\begin{array}{l}\text { Olay } \\
\text { No }\end{array}$} & \multicolumn{2}{|c|}{ Shapiro Wilk p Değerleri } & Bağımsız t Testi p Değerleri & Mann-Whitney p Değerleri \\
\hline & $\begin{array}{l}\text { Olay Öncesi } \\
\text { CAR }(N=5)\end{array}$ & $\begin{array}{l}\text { Olay Sonrası } \\
\text { CAR }(\mathrm{N}=5)\end{array}$ & $\begin{array}{cc}\text { Olay Öncesi } & \text { Olay Sonrası } \\
\text { CAR }(N=5) & \text { CAR }(N=5)\end{array}$ & $\begin{array}{l}\text { Olay Öncesi } \\
\text { CAR }(\mathbf{N}=5)\end{array}$ \\
\hline o1 & $0,693 *$ & $0,197 *$ & $0,023 *$ & $0,009^{*}$ \\
\hline o2 & $0,428 *$ & $0,272 *$ & $0,031 *$ & $0,028 *$ \\
\hline o3 & $0,378 *$ & $0,949 *$ & 0,558 & 0,601 \\
\hline o5 & $0,635^{*}$ & $0,076^{*}$ & 0,939 & 0,916 \\
\hline o6 & $0,288 *$ & $0,342 *$ & 0,114 & 0,117 \\
\hline o8 & $0,853 *$ & $0,475 *$ & $0,0006^{*}$ & $0,009 *$ \\
\hline 010 & $0,537 *$ & $0,689 *$ & $0,002 *$ & $0,009 *$ \\
\hline o11 & $0,108 *$ & $0,760 *$ & $0,000 *$ & $0,009 *$ \\
\hline o12 & 0,008 & 0,21 & $0,0004 *$ & $0,009 *$ \\
\hline o13 & $0,834 *$ & $0,243 *$ & $0,006^{*}$ & $0,009 *$ \\
\hline o17 & $0,607 *$ & $0,390 *$ & $0,007 *$ & $0,028 *$ \\
\hline o18 & $0,425 *$ & $0,083 *$ & $0,059 * *$ & $0,047 *$ \\
\hline o20 & $0,331 *$ & $0,827 *$ & 0,446 & 0,347 \\
\hline $\mathrm{o} 21$ & $0,315 *$ & $0,243 *$ & 0,140 & 0,117 \\
\hline o22 & $0,304 *$ & $0,988^{*}$ & $0,000 *$ & $0,009 *$ \\
\hline 026 & $0,253 *$ & $0,841 *$ & $0,012 *$ & $0,028 *$ \\
\hline o29 & $0,668 *$ & $0,751 *$ & $0,006 *$ & $0,009 *$ \\
\hline o31 & $0,100 *$ & $0,972 *$ & $0,005 *$ & $0,009 *$ \\
\hline $\mathrm{o} 32$ & $0,896^{*}$ & $0,566^{*}$ & $0,0005^{*}$ & 0,601 \\
\hline o33 & $0,360 *$ & $0,976 *$ & $0,001 *$ & $0,009 *$ \\
\hline o38 & $0,363 *$ & $0,087 *$ & $0,002 *$ & $0,009 *$ \\
\hline $\mathrm{o} 41$ & $0,708 *$ & $0,239 *$ & $0,023 *$ & $0,028 *$ \\
\hline $\mathrm{o} 43$ & $0,098 *$ & $0,907 *$ & $0,0002 *$ & $0,009 *$ \\
\hline
\end{tabular}


Olumsuz bildirimlere ilişkin parametrik ve non-parametrik test sonuçları ise Tablo 6'da verilmiştir. İkisi hariç 18 olayda, Shapiro-Wilk p-değerleri 0,05'ten büyük elde edildiğinden hem olay öncesi dönemine hem de olay sonrası döneme ilişkin grupların normal dağıım gösterdiği anlaşılmaktadır. Dolayısıyla, bu 18 olay için Bağımsız Örneklem t testi yorumlanabilir niteliktedir. Bağımsız Örneklem $\mathrm{t}$ testi sonuçlarına göre, 18 olayın 7'sinda \%95 güven aralığında, 2'sinde \%90 güven aralığında anlamlı farklılık tespit edilmiştir. Parametrik olmayan Mann-Whitney testi de benzer sonuçlar vermiş olup, 20 adet olayın 8'inde \%95 güven aralığında, 2'sinde \%90 güven aralığında anlamlı farklılık gözlemlenmiştir. Dolayısıyla, olumsuz bildirimlerin yaklaşık yarısında, yapılan bildirimin pay senedinin fiyatını 5 işlem günü boyunca etkilediği ortaya çıkmaktadır. Bu sonuç da olumsuz bildirimlerin etkisinin ortalama olarak daha kısa sürdüğü şeklindeki tespitimizi teyit etmektedir.

Bu analizlerin sonuçları birlikte değerlendirildiğinde, Borsa İstanbul'daki şirketler tarafından gönüllü olarak geleceğe yönelik değerlendirmeler kapsamında yapılan özel durum bildirimlerinin genel olarak ilgili şirketin pay senedinin getirisini etkilediği; bu bildirimlerden olumsuz nitelikte olanların ilk etkisinin ortalama olarak olumlu nitelikte olanların ilk etkisinden daha güçlü olduğu; buna karşın süre olarak olumlu bildirimlerin etkisinin olumsuz bildirimlerin etkisinden daha uzun sürdüğü (ortalama olarak beş işlem gününe karşılık üç işlem günü), daha spesifik olarak belirtmek gerekirse, olumlu bildirimlerin yaklaşık dörtte üçünün açıklama sonrasındaki beş işlem gününe kadar pay senedi fiyatına etkide bulunmasına karşın olumsuz bildirimlerin ancak yarısına yakınında bu etkinin beş işlem gününe kadar çıktığı şeklinde istatistiksel olarak anlamlı bulgular elde edilmiştir.

Tablo 6. Olumsuz Bildirimler İçin Olay Öncesi ve Sonrası Kümülatif Anormal Getirilerine Iliş̧kin Shapiro-Wilk Testi, Bağımsız Örneklem t Testi ve Mann-Whitney Test Sonuçları

\begin{tabular}{|c|c|c|c|c|}
\hline \multirow[b]{2}{*}{$\begin{array}{c}\text { Olay } \\
\text { No }\end{array}$} & \multicolumn{2}{|c|}{ Shapiro Wilk p Değerleri } & Bağımsız t Testi p Değerleri & Mann-Whitney p Değerleri \\
\hline & $\begin{array}{l}\text { Olay Öncesi } \\
\text { CAR }(N=5)\end{array}$ & $\begin{array}{l}\text { Olay Sonrası } \\
\text { CAR }(N=5)\end{array}$ & $\begin{array}{lc}\text { Olay Öncesi } & \text { Olay Sonrası } \\
\text { CAR }(N=5) & \text { CAR }(N=5) \\
\end{array}$ & $\begin{array}{l}\text { Olay Öncesi } \\
\text { CAR }(\mathbf{N}=5)\end{array}$ \\
\hline o4 & $0,998 *$ & $0,663 *$ & $0,008^{*}$ & $0,016^{*}$ \\
\hline o7 & $0,205^{*}$ & $0,777 *$ & $0,000 *$ & $0,009 *$ \\
\hline o9 & $0,623 *$ & $0,592 *$ & $0,013 *$ & $0,009 *$ \\
\hline o14 & $0,411 *$ & $0,166^{*}$ & 0,283 & 0,250 \\
\hline o15 & $0,257 *$ & $0,708 *$ & 0,540 & 0,250 \\
\hline o16 & $0,239 *$ & $0,724 *$ & $0,061 * *$ & $0,075^{* *}$ \\
\hline o19 & $0,886^{*}$ & $0,335^{*}$ & 0,217 & 0,250 \\
\hline 023 & $0,838 *$ & $0,823 *$ & 0,665 & 0,754 \\
\hline $\mathrm{o} 24$ & 0,0005 & $0,803 *$ & $0,024 *$ & $0,009 *$ \\
\hline 025 & 0,0138 & $0,640 *$ & $0,061 * *$ & $0,075^{* *}$ \\
\hline 027 & $0,059 *$ & $0,279 *$ & $0,014 *$ & $0,016^{*}$ \\
\hline 028 & $0,162 *$ & $0,391 *$ & 0,573 & 0,464 \\
\hline 030 & $0,688 *$ & $0,853 *$ & $0,000 *$ & $0,009 *$ \\
\hline o34 & $0,845^{*}$ & 0,317 & $0,012 *$ & $0,009 *$ \\
\hline o35 & $0,719 *$ & $0,571 *$ & 0,969 & 0,754 \\
\hline o36 & $0,905 *$ & $0,177 *$ & 0,273 & 0,347 \\
\hline o37 & $0,920 *$ & $0,544 *$ & 0,339 & 0,347 \\
\hline o39 & $0,971 *$ & $0,174 *$ & $0,099 * *$ & 0,117 \\
\hline 040 & $0,060 *$ & $0,212 *$ & $0,0007 *$ & $0,009 *$ \\
\hline 042 & $0,904 *$ & $0,247^{*}$ & 0,864 & 0,754 \\
\hline
\end{tabular}

\section{Sonuç}

Şirketlerin geçmişe dönük finansal bilgilerinin yanı sıra geleceğe yönelik bilgileri açıklamaları yatırımcıların yatırım karar almalarına yardımcı olmakta, piyasadaki bilgi asimetrisini azaltmakta ve sermaye maliyetinin düşürülmesine katkıda bulunmaktadır. Bu nedenle, çok sayıda ülke, şirketlerin gönüllülük esası çerçevesinde bu bilgileri faaliyet raporları, özel durum açıklamaları, basın duyuruları veya yatırımcı sunuları kanalıyla kamuya açıklamalarını teşvik etmektedir. 
Türkiye'de Sermaye Piyasası Kurulu tarafından 2014 yılı başında yapılan düzenleme ile geleceğe yönelik değerlendirmelerin payları Borsa İstanbul'da işlem gören şirketlerce gönüllü olarak kamuya açıklanmasının esasları belirlenmiştir. Bu düzenleme sayesinde, şirketlerin geleceğe yönelik değerlendirmelerini faaliyet raporları dışında özel durum açıklaması yoluyla kamuya duyurmaları imkânı getirilmiştir. Bu imkân ile birlikte, geçen 5 yıllık sürede gönüllü de olsa çok sayıda özel durum açıklaması yapılmış, dolayısıyla analize elverişli veri oluşmuştur.

Bu çerçevede, çalışmada, 23.01.2014 - 23.01.2019 döneminde payları Borsa İstanbul'da işlem gören şirketlerin geleceğe yönelik bildirimler kapsamında yaptıkları özel durum açıklamalarının söz konusu şirketlerin pay senedi fiyatlarına etkisi ampirik olarak test edilmiştir. Çalışmanın sonuçlarına göre; ilk olarak, geleceğe yönelik değerlendirmeler kapsamında yapılan özel durum açıklamalarııın pay senedinin getirisini etkilediğine ve dolayısıyla da yatırımcıların bu tür açıklamalara duyarlı olduğuna dair istatistiksel olarak anlamlı bulgulara ulaşılıştır. İinci olarak, söz konusu bildirimlerden olumlu olanların anormal getiri etkisinin ortalama olarak açıklamadan itibaren beş işlem gününe kadar, olumsuz bildirimlerin anormal getiri etkisinin ise ortalama olarak üç işlem gününe kadar sürdüğü anlaşılmıştır. Üçüncü olarak, olumsuz bildirimlerin ilk etkisinin olumlu bildirimlerin ilk etkisinden daha güçlü olduğu ortaya konulmuştur.

$\mathrm{Bu}$ kapsamda, yatırımcıların geleceğe yönelik değerlendirmelere duyarlı olduğu ve bu değerlendirmelerin pay senedinin getirisini etkilediğine ilişkin bulgulara ulaşıldığından, bu konudaki düzenlemelerin geliştirilmesi, özellikle de söz konusu değerlendirmelerin faaliyet raporları yerine özel durum açıklaması yoluyla kamuya duyurulmasının teşvik edilmesi ve bu açıklamaların içeriği ve zamanlaması konusunda standartlar belirlenmesi önerilmektedir. Öte yandan, bundan sonraki araştırmalarda, bu defa özel durum açıklamaları ile kamuya açıklanan geleceğe yönelik değerlendirmelerde yer alan bilgilerden yola çıkılarak, bu değerlendirmelerin açıklanmasını etkileyen faktörlerin, açıklama içeriklerinin kalitesi ile nitel ve nicel özelliklerinin analiz edilmesi yararlı olacaktır.

\section{Kaynaklar}

Ackert, L. F., Church, B. K., \& Sankar, M. R. (1998). Voluntary disclosure under imperfect competition experimental evidence. Federal Reserve Bank of Atlanta Working Paper, 98-7.

Akbulut, Y. (2011). Sosyal bilimlerde SPSS uygulamaları. İstanbul: Ideal Yayıncılık.

Aljifri, K., \& Hussainey, K. (2007). The determinants of forward-looking information in annual reports of UAE companies. Managerial Auditing Journal, 22(9), 881-894.

Alkhatib, K. (2014). The determinants of forward-looking information disclosure. Procedia - Social and Behavioral Sciences, 109, 858-864.

Amir, E., \& Lev, B. (1996), Value-relevance of nonfinancial information: The wireless communications industry. Journal of Accounting and Economics, 22(1-3), 3-30

Baginski, S. P., Hassell, J. M., \& Kimbrough, M. D. (2004). Why do managers explain their earnings forecasts. Journal of Accounting Research, 42(1), 1-29.

Barron, O. E., Kile C. O., \& O'Keefe, T. B. (1999). MD\&A quality as measured by the SEC and analysts' earnings forecasts. Contemporary Accounting Research, 16(1), 75-109

Beattie, V. A., McInnes B., \& Fearnley, S. (2004). A methodology for analysing and evaluating narratives in annual reports: A comprehensive description profile and metrics for disclosure quality attributes. Accounting Forum, 28(3), 205-236.

Beretta, S., \& Bozzolan, S. (2008). Quality versus quantity: The case of forward-looking disclosure. Journal of Accounting, Auditing \& Finance, 23(3), 333-375.

Botosan, C. A. (1997). Disclosure level and the cost of capital. Accounting Review, 72(3), 323-349.

Botosan, C. A., \& Plumlee, M. A. (2002). A re-examination of disclosure level and the expected cost of equity capital. Journal of Accounting Research, 40(1), 21-40.

Bozzolan, S., Favotto, F., \& Ricceri, F. (2003). Italian annual Intellectual capital disclosure: An empirical analysis. Journal of Intellectual Capital, 4(4), 543-558. 
Bozzolan, S., Trombetta, M., \& Beretta, S. (2009). Forward looking disclosures, financial verifiability and analysts' forecasts: A study of cross-listed European firms. European Accounting Review, 18(3), 435-473.

Bravo, F. (2016). Forward-looking disclosure and corporate reputation as mechanismsto reduce stock return volatility. Revista de Contabilidad, 19(1), 122-131.

Bryan, S. H. (1997). Incremental information content of required disclosures contained in management discussion and analysis. The Accounting Review, 72(2), 285-301.

Büyüköztürk, Ş. (2012). Sosyal bilimler için veri analizi el kitabı (16. Baskı). Ankara: Pegem Akademi Yayıncılık

Clarkson, P., Kao, J., \& Richardson, G. (1994). The voluntary inclusion of forecasts in the MD\&A section of annual reports. Contemporary Accounting Research, 11 (1), 423-450.

Clarkson, P., Kao, J., \& Richardson, G. (1999). Evidence that management discussion and analysis (MD\&A) is a part of a firm's overall disclosure package. Contemporary Accounting Research, 16(1), 111-134.

Çelik, O., Ecer, A., \& Karabacak, H. (2006). Disclosure of forward looking information: Evidence from listed companies on Istanbul Stock Exchange (ISE). Investment Management and Financial Innovations, 3(2), 197-216.

Cootner, P. H. (1964). The random character of stock market prices. Cambridge: MIT Press.

Core, J. (2001). A review of the empirical disclosure literature discussion. Journal of Accounting and Economics, 31(1-3), 441-456.

Dontoh, A. (1989). Voluntary disclosure. Journal of Accounting, Auditing and Finance 4, Fall 1989, 480-511.

Drake, P. D., \& Peavy, J. W. (1995). Fundamental analysis, stock prices and the demise of the miniscribe corporation. Journal of Portfolio Management, Spring, 68-73.

Dutta, S., \& Trueman, B. (2002). The interpretation of information and corporate disclosure strategies. Review of Accounting Studies, 7(1), 75-76.

Eaton, T. V., \& Stanga, K. G. (2000). An ex ante test of the Jenkins committee disclosure recommendations. Advances in Accounting, 17, 245-258.

Eyüboğlu, K., \& Bulut, H. i. (2016). Şirketlere özgü haberlerin hisse performansına etkisi: BIST-30 şirketleri örneği. Uluslararası iktisadi ve Idari Incelemeler Dergisi, 16, 113-138.

Francis, J., Lafond, R., Olsson, P., \& Schipper, K. (2004). Costs of equity and earnings attributes. The Accounting Review, 79(4), 967-1010.

Frankel, R., Mcnichols, M., \& Wilson, G. P. (1995). Discretionary disclosure and external financing. Accounting Review, 70(1), 135-150.

Frost, C. A. (1996). Characteristics and information value of corporate disclosures of forward looking information in global equity markets. Washington University St. Louis Olin, School of Business Working Papers, 96-13, June 1996.

Healy P., \& Palepu, K. (2001). Information asymmetry, corporate disclosure, and the capital markets: A review of -the empirical disclosure literature. Journal of Accounting and Economics, 31, 405-440

Kent, P., \& Ung, K. (2003). Voluntary disclosure of forward-looking earnings information in Australia. Australian Journal of Management, 28(3), 273-285.

Kılıç, S. (2011). IMKB kurumsal yönetim endeksine dahil olan şirketlerin getiri performanslarının ölçülmesi. Finans Politik ve Ekonomik Yorumlar Dergisi, 48(552), 45-58.

Krishnan, M., Sankaraguruswamy, S., \& Shin, H. (1996). Skewness of earnings and the believability hypothesis: How does the financial market discount accounting disclosures? University of Minnesota Working Paper.

Lam, S. S., \& Du, J. (2004). Information asymmetry and estimation risk: Preliminary evidence from Chinese equity markets. Pacific-Basin Finance Journal, 12(1), 311-331.

Lang, M., \& Lundholm, R. (1996). Corporate disclosure policy and analyst behavior. Accounting Review, 71(1), 467-492.

Leuz, C., \& Verrecchia, R. E. (2000). The economic consequences of increased disclosure. Journal of Accounting Research, 38(1), 91-124.

Lundholm, R., \& Van Winkle, M. (2006). Motives for disclosure and non-disclosure: A framework and review of the evidence. Accounting and Business Research, 36(1), 43-48.

Menicucci, E. (2013). Firms' characteristics and forward-looking information in management commentaries of Italian listed companies. African Journal of Business Management, 7(17), 1667-1674. 
Miller, G. S., \& Piotroski, J. D. (2000). Forward-looking earnings statements: determinants and market response. http://ssrn.com/abstract=238593 (Erişim tarihi: 22.02.2019).

Peters, S. J., \& Schacht, K. J. D. (2014). Forward-Looking information: A necessary consideration in the SEC's review on disclosure effectiveness: Investor perspectives. CFA Institute Position Paper. https://www.cfainstitute.org//media/documents/article/position-paper/forward-looking-information-a-necessary-consideration-in-secreview.ashx (Erişim tarihi: 25.02.2019).

Sengupta, P. (1998). Corporate disclosure quality and the cost of debt. Accounting Review, 73(1), 459-474.

Skinner, D. J. (1994). Why firms voluntarily disclose bad news. Journal of Accounting Research, 32(1), 38-60.

Skogsvik, K. (1998). Conservative accounting principles equity valuation and the importance of voluntary disclosures. British Accounting Review, 30(1), 361-381.

Tutino, M., Regoliosi C., \& D’Eri A. (2013). Forward-looking quantitative information in Italian listed firms. Empirical evidence in 2006-2010. Corporate Ownership \& Control, 11(1-1), 47-61.

Qu, W., Ee, M., Liu, L, Wise, V., \& Carey, P. (2015). Corporate governance and quality of forward-looking information: Evidence from the Chinese stock market. Asian Review of Accounting, 23(1).

Uyar, A., \& Kılıç, M. (2012). Influence of corporate attributes on forward-looking information disclosure in publicly traded Turkish corporations. Procedia-Social and Behavioral Sciences, 62, 244-252.

Vanstraelen, A., Zarzeski, M. T., \& Robb, S. W. G. (2003). Corporate nonfinancial disclosure practices and financial analyst forecast ability across three European countries. Journal of International Financial Management and Accounting, 14(3), 249-278.

Wagenhofer, A. (1990). Voluntary disclosure with a strategic opponent. Journal of Accountingand Economics, 12(4), 341363.

www.finnet.com.tr

www.kap.org.tr

www.spk.gov.tr 